\title{
Eight new apterous Lathrobium species (Coleoptera, Staphylinidae) from Sichuan, Southwest China
}

\author{
Zhong Peng ${ }^{1, \dagger}$, Li-Zhen Li ${ }^{1, \neq}$, Mei-Jun Zhao ${ }^{1, \S}$ \\ I Department of Biology, College of Life and Environmental Sciences, Shanghai Normal University, Shanghai, \\ 200234, P. R. China \\ † urn:lsid:zoobank.org:author:6CDD4A22-46AC-4DAF-8409-6D1922AE5D81 \\ $\ddagger$ urn:lsid:zoobank.org:author:BBACC7AE-9B70-4536-ABBE-54183D2ABD45 \\ § urn:lsid:zoobank.org:author:FBE4FA1F-5BCF-405E-98C1-4F86894643EA \\ Corresponding author: Mei-Jun Zhao (mjzhao@shnu.edu.cn)
}

Academic editor: Volker Assing | Received 16 April 2013 | Accepted 17 May 2013 | Published 21 May 2013

urn:lsid:zoobank.org:pub:B923E8D5-426B-48DF-9D28-243B37C35D8D

Citation: Peng Z, Li L-Z, Zhao M-J (2013) Eight new apterous Lathrobium species (Coleoptera, Staphylinidae) from Sichuan, Southwest China. ZooKeys 303: 1-21. doi: 10.3897/zookeys.303.5328

\begin{abstract}
Eight apterous species of the paederine genus Lathrobium Gravenhorst, 1802 from the Chinese province Sichuan are described, illustrated, and distinguished from closely related and/or geographically close congeners: L. erlangense Peng \& Li sp. n. (Erlang Shan), L. blandum Peng \& Li sp. n. (Labahe N. R.), L. yelense Peng \& Li sp. n. (Yele), L. obscurum Peng \& Li sp. n. (Yele), L. yinziweii Peng \& Li sp. n. (Yele), L. illustre Peng \& Li sp. n. (Yele), L. micangense Peng \& Li sp. n. (Micang Shan) and L. agglutinatum Assing \& Peng sp. n. (Qingcheng Shan). The total number of described Lathrobium species from Sichuan now stands at 39, that of mainland China at 165.
\end{abstract}

\section{Keywords}

Coleoptera, Staphylinidae, taxonomy, Lathrobium, new species, Sichuan, China

\section{Introduction}

So far, 157 species of the genus Lathrobium Gravenhorst have been reported from mainland China and the diversity is significantly greater than that of any other genus of the Paederinae. The provinces with the greatest diversity are Yunnan (58 species),

Copyright Zhong Peng et al. This is an open access article distributed under the terms of the Creative Commons Attribution License 3.0 (CC-BY), which permits unrestricted use, distribution, and reproduction in any medium, provided the original author and source are credited. 
followed by Sichuan (31 species), Shaanxi (20 species), and Zhejiang (17 species). However, these figures are still strongly biased. They do not reflect real diversities, but rather are a result of imbalanced collecting and study activity (Assing, in press a).

The topology of Sichuan is dominated by mountain regions (49.5\%) and plateau (28.5\%). The highest peak of Sichuan is the Gongga Shan at 7,556 m. East Sichuan is subject to the subtropical monsoon climate and the west is influenced by plateau alpine climate. Pine and beech forests form the main forest types in Sichuan (Yang 1988).

Schülke (2002) was the first to describe a micropterous Lathrobium species from Sichuan. Thirty additional species, most of them micropterous and locally endemic, were subsequently reported from this province by Peng et al. (2012), Assing et al. (2013) and Assing (in press b, c, d). In Sichuan, Lathrobium species have been described from the Emei Shan (6 species), the Gongga Shan (3 species), the Erlang Shan (3 species), the Labahe Nature Reserve (2 species), the Luoji Shan (3 species), the Xilingxue Shan (2 species), the region to the northwest of Kangding in the Daxue Shan (1 species), the Daxiang Ling (1 species), the Min Shan and adjacent mountain ranges in northern Sichuan (4 species), the Micang Shan at the border with Shaanxi (4 species), the region to the north of Jinyang in southern Sichuan (1 species), and the region to the northwest of Muli County in the Hengduan mountains (1 species). A map of the Lathrobium species from Sichuan Province is provided in Fig. 1.

In recent years, we surveyed the staphylinid fauna of several nature reserves in Sichuan Province (Erlang Shan; Labahe N. R.; Micang Shan; Qingcheng Shan and Yele), and collected numerous Lathrobium specimens. An examination of the material yielded eight undescribed apterous species, all remarkably different from the previously known species from China with respect to the male sexual characters.

\section{Material and methods}

The following abbreviations are used in the text, with all measurements in millimeters:

BL length of body from the anterior margin of the labrum to the apex of the abdomen;

FL length of forebody from the anterior margin of the labrum to the posterior margin of the elytra;

HL from the anterior margin of the frons to the posterior margin of the head;

HW maximum width of head;

PL length of pronotum along midline;

PW maximum width of pronotum;

EL length of elytra from the apex of the scutellum to the posterior margin of the elytra;

AL length of the aedeagus from the apex of the ventral process to the base of the aedeagal capsule.

The type material is deposited in the Insect Collection of Shanghai Normal University, Shanghai, China (SNUC) and in the private collection of Volker Assing, Hannover (cAss). 


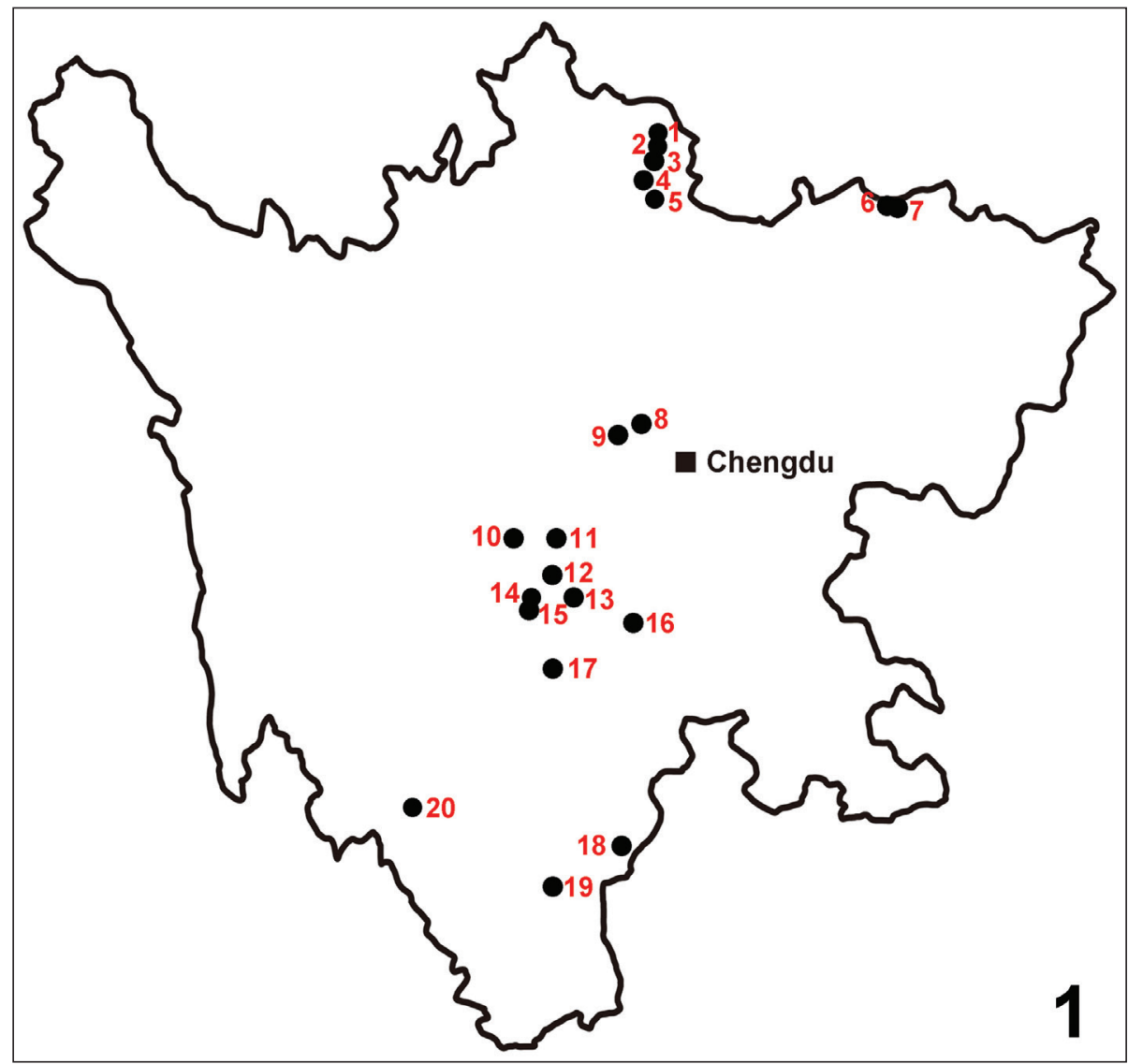

Figure I. Distribution of the Lathrobium species in Sichuan: L. biapicale (1-5); L. detruncatum (4); L. lentum (4); L. brevisternale (5); L. crassispinosum (6); L. sinense (6); L. longispinosum (6); L. serrilobatum (7); L. micangense (7); L. agglutinatum (8); L. bisuditum (9); L. verminatum (9); L. watanabei (10); L. acutissimum (11); L. labahense (11); L. blandum (11); L. aspinosum (12); L. bibaculatum (12); L. bispinigerum (12); L. erlangense (12); L. bihastatum (13); L. hailuogouense (14); L. celere (15); L. ventricosum (15); L. bisinuatum (16); L. conexum (16); L. coniunctum (16); L. ensigerum (16); L. hastatum (16); L. iunctum (16); L. yelense (17); L. yinziweii (17); L. obscurum (17); L. illustre (17); L. appendiculatum (18); L. bivirgatum (19); L. diffssum (19); L. hamulatum (19); L. formidabile (20).

\section{Taxonomy}

\section{Lathrobium erlangense Peng \& Li, sp. $\mathrm{n}$.} urn:Isid:zoobank.org:act:3340FD66-09D4-48F5-8DAD-FC27B9492E84 http://species-id.net/wiki/Lathrobium_erlangense

Figs 2A, 3, 13

Type material. $(1 \hat{\jmath}, 2+$ 우). Holotype: $\widehat{\partial}$, labelled 'CHINA: Sichuan Prov., Tianquan County Mt. Erlangshan, $29^{\circ} 52^{\prime} \mathrm{N}, 102^{\circ} 18^{\prime} \mathrm{E}, 13 . v i i .2012$ alt. 2,200-2,300 m, Dai, Peng \& Yin leg.' (SNUC). Paratypes: 2 q 9 , same label data as holotype (SNUC). 
Description. Measurements (in $\mathrm{mm}$ ) and ratios: BL 5.84-8.06, FL 2.82-3.25, HL 0.83-0.92, HW 0.87-0.94, PL 1.17-1.26, PW 0.93-1.00, EL 0.56-0.67, AL 1.30, HL/HW 0.95-0.98, HW/PW 0.94, HL/PL 0.70-0.73, PL/PW 1.26, EL/PL $0.48-0.53$.

Habitus as in Fig. 2A. Body brown with paler apex, legs yellowish brown, antennae light brown.

Head subquadrate, distinctly dilated posteriorly; punctation coarse and of variable density, sparser in median dorsal area; interstices with fine microreticulation; eyes 1/4 times as long as postocular region in dorsal view.

Pronotum nearly parallel-sided; punctation somewhat sparser than that of head; impunctate midline broad; interstices without microsculpture.

Elytra approximately $0.48-0.53$ times as long as pronotum; punctation fine, shallow, and moderately dense. Hind wings completely reduced. Protarsi with weakly pronounced sexual dimorphism.

Abdomen with moderately fine and dense punctation, that of tergite VII noticeably sparser than that of anterior tergites; interstices with fine microsculpture; posterior margin of tergite VII without palisade fringe; tergite VIII without sexual dimorphism, convexly produced posteriorly (Fig. 3A).

Male. Sternites III-VI unmodified; sternite VII (Fig. 3D) transverse, symmetric, and with median impression of subtriangular shape posteriorly, this impression with cluster of distinctly modified, short and stout black setae, posterior margin weakly concave in the middle; sternite VIII (Fig. 3E) transverse, symmetric, and with shallow median impression, on either side of middle with cluster of weakly modified dark setae posteriorly, posterior excision small and of semi-circular shape; aedeagus (Figs $3 \mathrm{~F}, 3 \mathrm{H}$ ) with ventral process of distinctive shape, apical portion of dorsal plate long, lamellate and moderately sclerotized, basal portion of dorsal plate very short and weakly sclerotized, internal sac with distinctly sclerotized spines.

Female. Sternite VIII (Fig. 3B) much longer than tergite VIII, distinctly produced and finely pubescent posteriorly; tergite X (Fig. 3C) 1.1 times as long as the undivided antero-median portion of tergite IX (Fig. 3C).

Distribution and biological notes. The species is known only from one locality in the Erlang Shan, Sichuan. The specimens were collected at an altitude of 2,200-2,300 $\mathrm{m}$. The holotype was sifted from rhododendron leaves and soil on the east slope of a dry ditch in a rhododendron forest (Fig. 13).

Etymology. The species is named after the mountain where the type locality locality is situated ("Erlang Shan").

Comparative notes. Based on the male and female sexual characters, L. erlangense undoubtedly belongs to the L. bibaculatum group (Assing, in press c). The similarly derived morphology of the aedeagus (somewhat spear-shaped ventral process, rather massive internal spines), as well as the similar modifications of the male sternites VII and VIII suggest that it is the adelphotaxon of L. bibaculatum Assing (in press c) from the Daxiang Ling, from which it is distinguished by somewhat smaller body size and by the more slender ventral process of the aedeagus. 


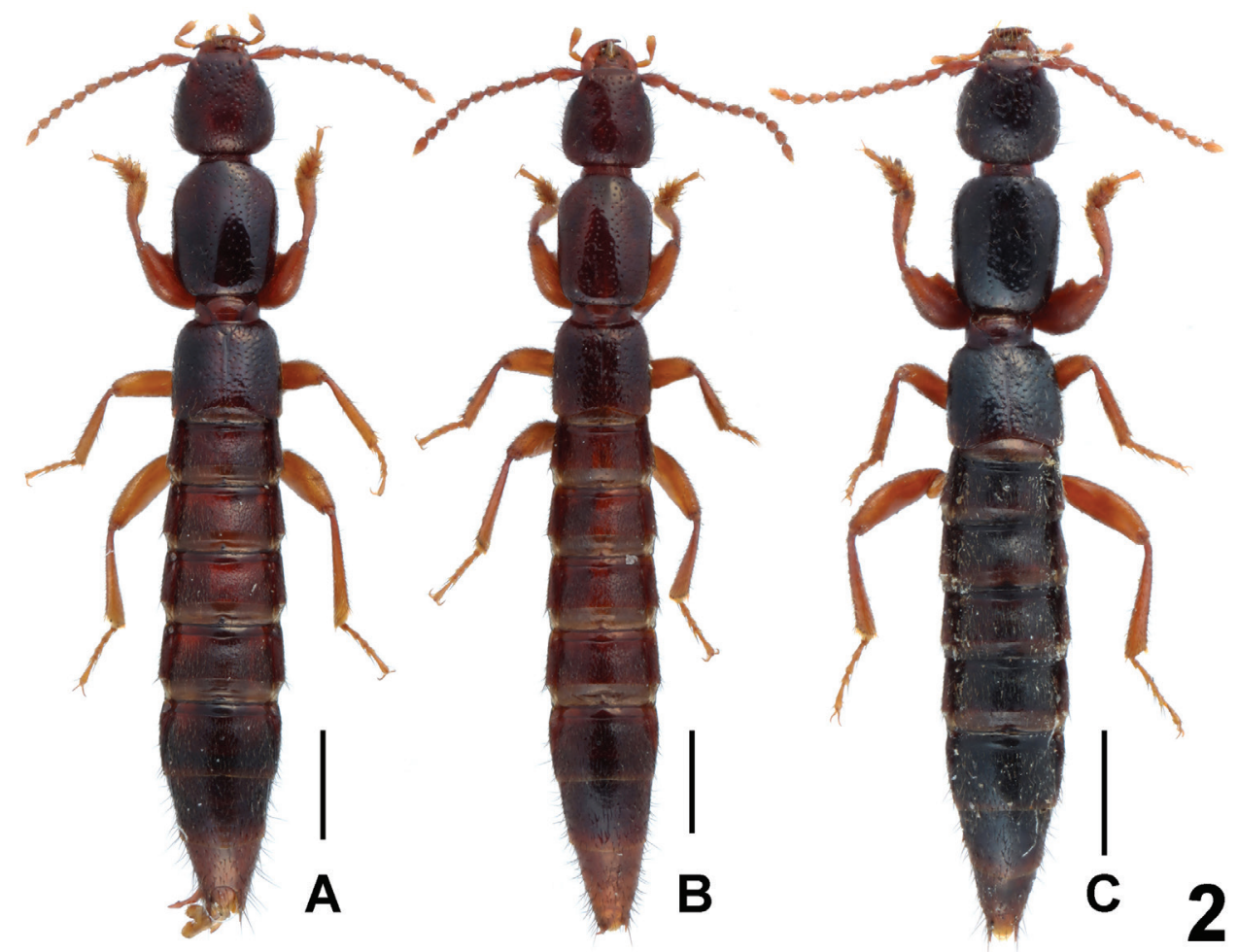

Figure 2. Habitus of Lathrobium spp., A L. erlangense B L. blandum C L. yelense. Scale bars: $1.0 \mathrm{~mm}$.

\section{Lathrobium blandum Peng \& Li, sp. n.} urn:lsid:zoobank.org:act:851DA1BD-04AD-4C4B-8258-C885CA682F6E http://species-id.net/wiki/Lathrobium_blandum

Figs 2B, 4, 14

Type material. ( 1 §). Holotype: $\lesssim$, labelled 'CHINA: Sichuan Prov., Tianquan County Labahe N. R., $30^{\circ} 10^{\prime} \mathrm{N}, 102^{\circ} 25^{\prime} \mathrm{E}, 12 . v i i .2012$ alt. 2,200-2,300 m, Dai, Peng \& Yin leg.' (SNUC).

Description. Measurements (in mm) and ratios: BL 8.62, FL 3.39, HL 0.98, HW 0.94, PL 1.31, PW 0.98, EL 0.70, AL 1.72, HL/HW 1.04, HW/PW 0.96, HL/PL 0.75 , PL/PW 1.34, EL/PL 0.53.

Habitus as in Fig. 2B. Body light brown with paler apex, legs yellowish brown, antennae light brown.

Head weakly oblong; punctation moderately coarse and sparse, sparser in median dorsal portion; interstices with shallow microreticulation; eyes $1 / 5$ times as long as postocular region in dorsal view.

Pronotum slender; punctation similar to that of head; impunctate midline moderately broad; interstices without microsculpture. 


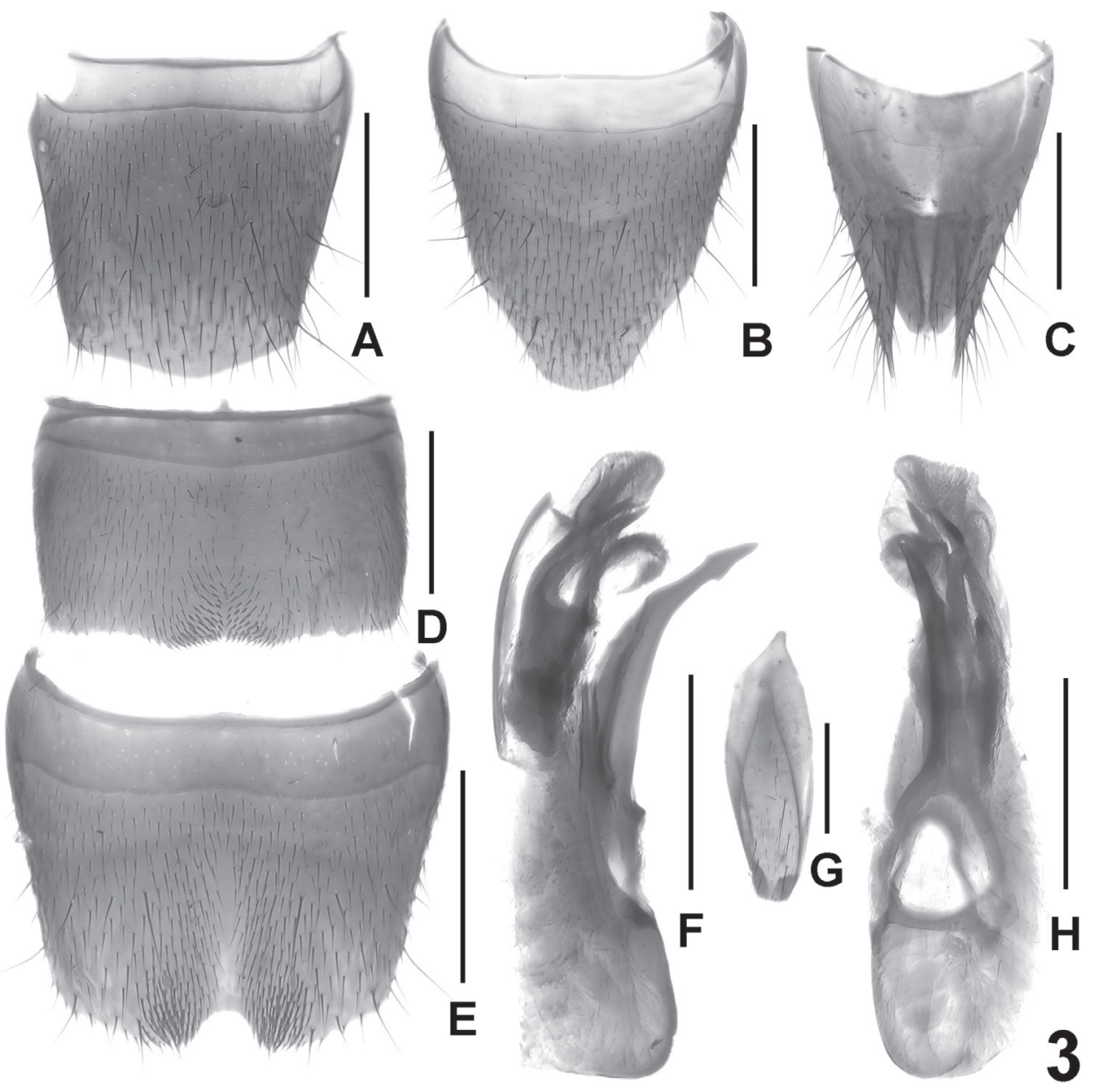

Figure 3. Lathrobium erlangense. A female tergite VIII B female sternite VIII C female tergites IX-X D male sternite VII E male sternite VIII $\mathbf{F}$ aedeagus in lateral view $\mathbf{G}$ male sternite IX $\mathbf{H}$ aedeagus in ventral view. Scale bars: $0.5 \mathrm{~mm}$.

Elytra 0.53 times as long as pronotum; punctation shallow, moderately dense, and rather weakly defined. Hind wings completely reduced.

Abdomen with fine and dense punctation, that of tergite VII sparser than that of anterior tergites; interstices with fine microsculpture; posterior margin of tergite VII without palisade fringe.

Male. Sternites III-VI unmodified; sternite VII (Fig. 4A) transverse and with shallow postero-median impression, this impression with weakly modified setae, posterior margin concave in the middle; sternite VIII (Fig. 4B) transverse and impressed along the middle, on either side of this impression with short setae posteriorly, posterior margin broadly concave; sternite IX (Fig. 4D) nearly symmetric; aedeagus as in 


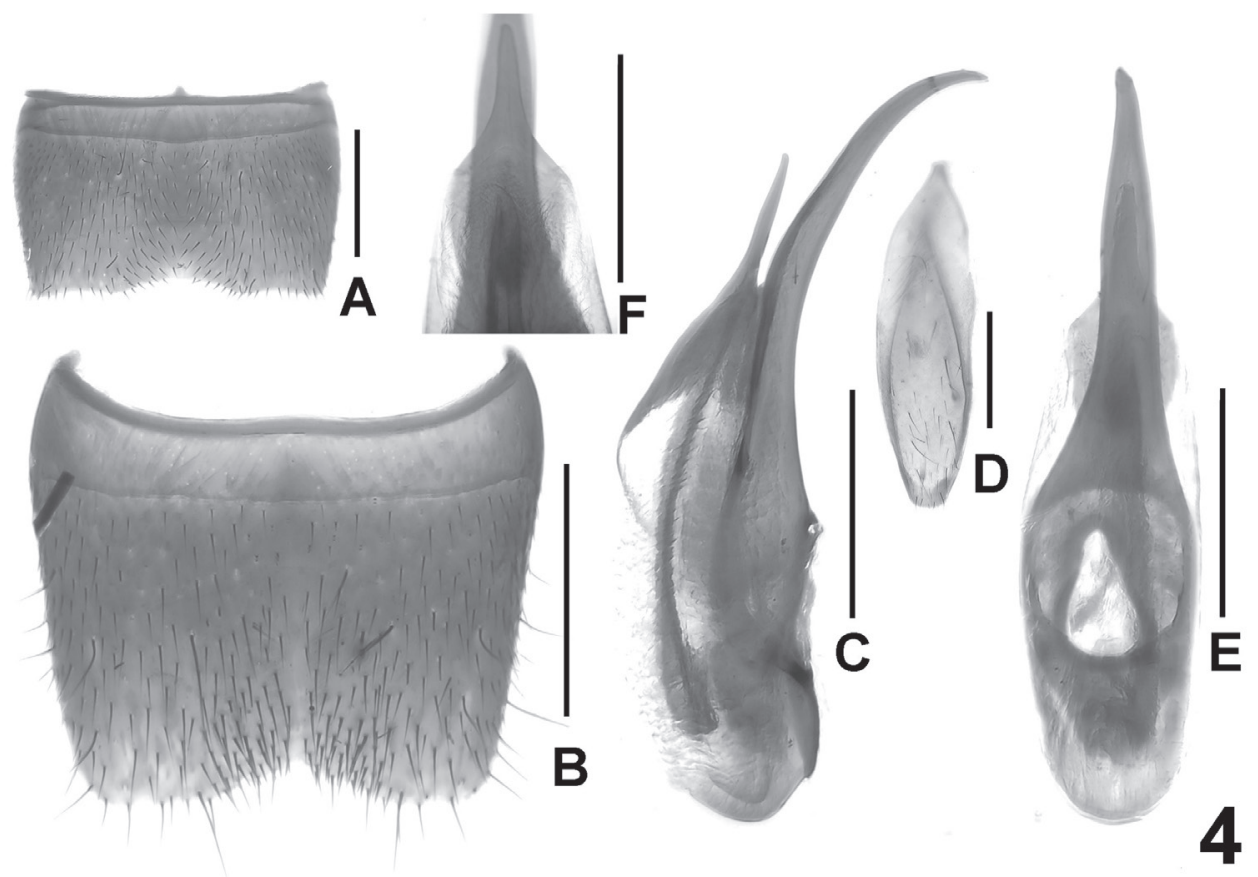

Figure 4. Lathrobium blandum. A male sternite VII B male sternite VIII C aedeagus in lateral view D male sternite IX $\mathbf{E}$ aedeagus in ventral view $\mathbf{F}$ apical portion of aedeagus in dorsal view. Scale bars: $0.5 \mathrm{~mm}$.

Figs 4C, 4E; ventral process evenly curved, slender, and apically acute in lateral view; dorsal plate (Fig. 4F) moderately sclerotized and with long apical portion, apically acute in dorsal view; basal portion short and thin; internal sac with long and slender sclerotized spine.

Female. Unknown.

Distribution and biological notes. The species is known only from one locality in the Labahe Natural Reserve, Sichuan. The holotype was collected by sifting leaf litter and weeds from the floor of the hardwood forest with Morus cathayana and Lonicera on a westward slope at an altitude of 2,200-2,300 m (Fig. 14).

Etymology. The specific epithet (Latin, adjective: seductive) alludes to the long and slender internal spine of the aedeagus.

Comparative notes. The morphology of the aedeagus suggests that $L$. blandum belongs to the L. curvatissimum group (Assing, in press a), which previously included five species from Yunnan (Assing, in press a) and two species from Sichuan (Assing, in press $\mathrm{b}, \mathrm{c}$ ), with which the new species shares the elongated and curved ventral process, and the long apical portion of the dorsal plate of the aedeagus. It is distinguished from the other representatives of this group by the less slender head, the shape and chaetotaxy of the male sternites VIII, as well as by the long and slender sclerotized spine in the internal sac of aedeagus. 


\section{Lathrobium yelense Peng \& Li, sp. n.}

urn:Isid:zoobank.org:act:3C6F3FB3-37B7-4289-8A1C-5A3D6A93AE7C

http://species-id.net/wiki/Lathrobium_yelense

Figs 2C, 5, 15

Type material. ( $4 \hat{\jmath} \widehat{\partial}, 2$ q $ᄋ$ ). Holotype: $\widehat{\jmath}$, labelled 'CHINA: Sichuan Prov., Shimian County, Liziping. Yele, 28 $54^{\prime} \mathrm{N}, 102^{\circ} 13^{\prime} \mathrm{E}, 15 . v i i .2012$ alt. 2,600 m, Dai, Peng \& Yin leg.' (SNUC). Paratypes: $3 \hat{\jmath} \widehat{\jmath}, 2$ 우, same label data as holotype (SNUC).

Description. Measurements (in $\mathrm{mm}$ ) and ratios: BL 5.95-7.39, FL 2.83-3.20, HL 0.87-0.93, HW 0.88-0.92, PL 1.15-1.18, PW 0.92-0.96, EL 0.63-0.70, AL 1.24-1.29, HL/HW 0.99-1.01, HW/PW 0.94-0.96, HL/PL 0.76-0.79, PL/PW 1.23-1.25, EL/PL 0.55-0.59.

Habitus as in Fig. 2C. Body blackish brown with paler apex, legs and antennae brown to light brown.

Head subquadrate; punctation moderately coarse and rather sparse, slightly sparser in median dorsal portion; interstices with fine microreticulation; eyes $1 / 4$ times as long as postocular region in dorsal view.

Pronotum nearly parallel-sided; punctation similar to that of head; impunctate midline moderately broad; interstices without microsculpture.

Elytra $0.55-0.59$ times as long as pronotum; punctation moderately dense, shallow, and weakly defined. Hind wings completely reduced. Protarsi with moderately pronounced sexual dimorphism.

Abdomen with fine and dense punctation, that of tergite VII slightly sparser than that of anterior tergites; interstices with shallow microsculpture; posterior margin of tergite VII without palisade fringe; tergite VIII with moderately pronounced sexual dimorphism.

Male. Tergite VIII with weakly convex posterior margin; sternites III-VI unmodified; sternite VII (Fig. 5D) transverse, with weakly modified setae in shallow posteromedian impression, posterior margin concave in the middle; sternite VIII (Fig. 5E) moderately transverse and impressed along the middle, on either side of this impression with numerous short and dark setae posteriorly, posterior margin shallowly concave in the middle; sternite IX (Fig. 5F) nearly symmetric; aedeagus as in Figs 5G, 5H; ventral process long and apically curved in lateral view; dorsal plate (Fig. 5I) weakly sclerotized and with long apical portion, apically acute in dorsal view; basal portion very short and thin; internal sac without distinct dark membranous structures and apically with moderately sclerotized structure.

Female. Tergite VIII (Fig. 5A) asymmetrically produced posteriorly; sternite VIII (Fig. 5B) longer than tergite VIII, distinctly produced posteriorly, posteriorly finely pubescent; tergite $\mathrm{X}$ (Fig. 5C) 0.4 times as long as the undivided antero-median portion of tergite IX (Fig. 5C). 


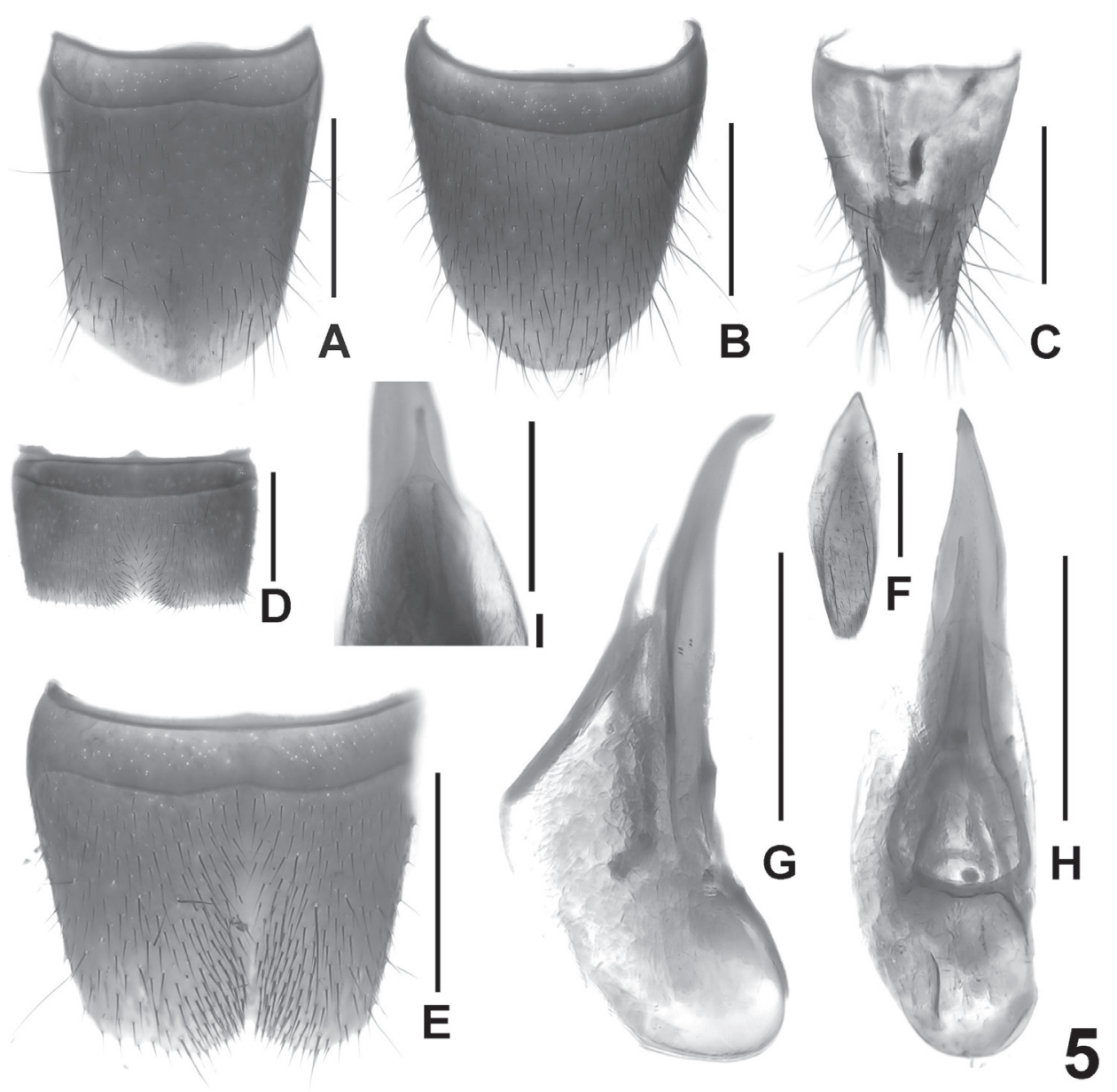

Figure 5. Lathrobium yelense. A female tergite VIII B female sternite VIII C female tergites IX-X. D male sternite VII E male sternite VIII $\mathbf{F}$ male sternite IX $\mathbf{G}$ aedeagus in lateral view $\mathbf{H}$ aedeagus in ventral view I apical portion of aedeagus in dorsal view. Scale bars: A-H $0.5 \mathrm{~mm} ; \mathbf{I} 0.25 \mathrm{~mm}$.

Distribution and biological notes. This species is currently known only from the type locality. Some of the type specimens were collected by sifting bamboo leaves and humus from the floor of a bamboo forest at an altitude of 2,600 m (Fig. 15).

Etymology. The species is named after its type locality: "Yele".

Comparative notes. Based on the male and female sexual characters, particularly the long and large dorsal plate, and the presence of an apical internal structure of the aedeagus, L. yelense may belong belongs to the L. ensigerum group (Assing et al. 2013). It is distinguished from the other representatives of this group by the sparser punctation on the head, the shape and chaetotaxy of the male sternite VIII, the oblong female tergite VIII, as well as by the morphology of the aedeagus. 


\section{Lathrobium obscurum Peng \& Li, sp. n.}

urn:lsid:zoobank.org:act:930E1048-C5E3-4923-B2C8-53F5DB650872

http://species-id.net/wiki/Lathrobium_obscurum

Figs 6A, 7

Type material. $\left(1{ }^{\lambda}\right)$. Holotype: $\partial^{\lambda}$, labelled 'CHINA: Sichuan Prov., Shimian County, Liziping. Yele, $28^{\circ} 54^{\prime} \mathrm{N}, 102^{\circ} 13^{\prime} \mathrm{E}, 15 . v i i .2012$ alt. 2,600 m, Dai, Peng \& Yin leg.' (SNUC).

Description. Measurements (in $\mathrm{mm}$ ) and ratios: BL 10.17, FL 4.10, HL 1.15, HW 1.20, PL 1.55, PW 1.20, EL 0.83, AL 2.38, HL/HW 0.96, HW/PW 1.00, HL/ PL 0.74, PL/PW 1.29, EL/PL 0.54.

Habitus as in Fig. 6A. Body blackish brown with paler apex, legs dark brown, antennae dark brown to brown.

Head weakly transverse; punctation coarse and moderately dense, sparser in median dorsal portion; interstices with fine microreticulation; eyes $1 / 4$ times as long as postocular region in dorsal view.

Pronotum nearly parallel-sided; punctation somewhat sparser than that of head; impunctate midline broad; interstices without microsculpture.

Elytra 0.54 times as long as pronotum; punctation fine, shallow, and moderately dense. Hind wings completely reduced.

Abdomen with fine and dense punctation, that of tergite VII sparser than that of anterior tergites; interstices with shallow microsculpture; posterior margin of tergite VII without palisade fringe.

Male. Sternites III-VI unmodified; sternite VII (Fig. 7A) strongly transverse, with median impression of triangular shape posteriorly, this impression with numerous distinctly modified, short and stout black setae; posterior margin distinctly concave in the middle; sternite VIII (Fig. 7B) transverse and broadly impressed along the middle, this impression with short modified setae, posterior margin shallowly concave in the middle; sternite IX (Fig. 7D) nearly symmetric; aedeagus as in Figs 7C, 7E; ventral process long, slender and evenly curved; dorsal plate (Fig. 7F) sclerotized and with long apical portion, apically acute in dorsal view and weakly curved in lateral view; basal portion short and thin; internal sac without sclerotized spines and with membranous structures.

Female. Unknown.

Distribution and biological notes. This species is currently known only from the type locality. The holotype was collected by sifting litter of bamboo and rhododendron from the floor of rhododendron forest at an altitude of 2,600 m.

Etymology. The specific epithet (Latin, adjective: dark) alludes to the dark brown coloration of the legs.

Comparative notes. The morphology of the aedeagus suggests that $L$. obscurum belongs to the L. curvatissimum group (Assing, in press a), which previously included five species from Yunnan (Assing, in press a) and two species from Sichuan (Assing, in press $\mathrm{b}, \mathrm{c}$ ), with which the new species shares the long, evenly curved ventral process, 


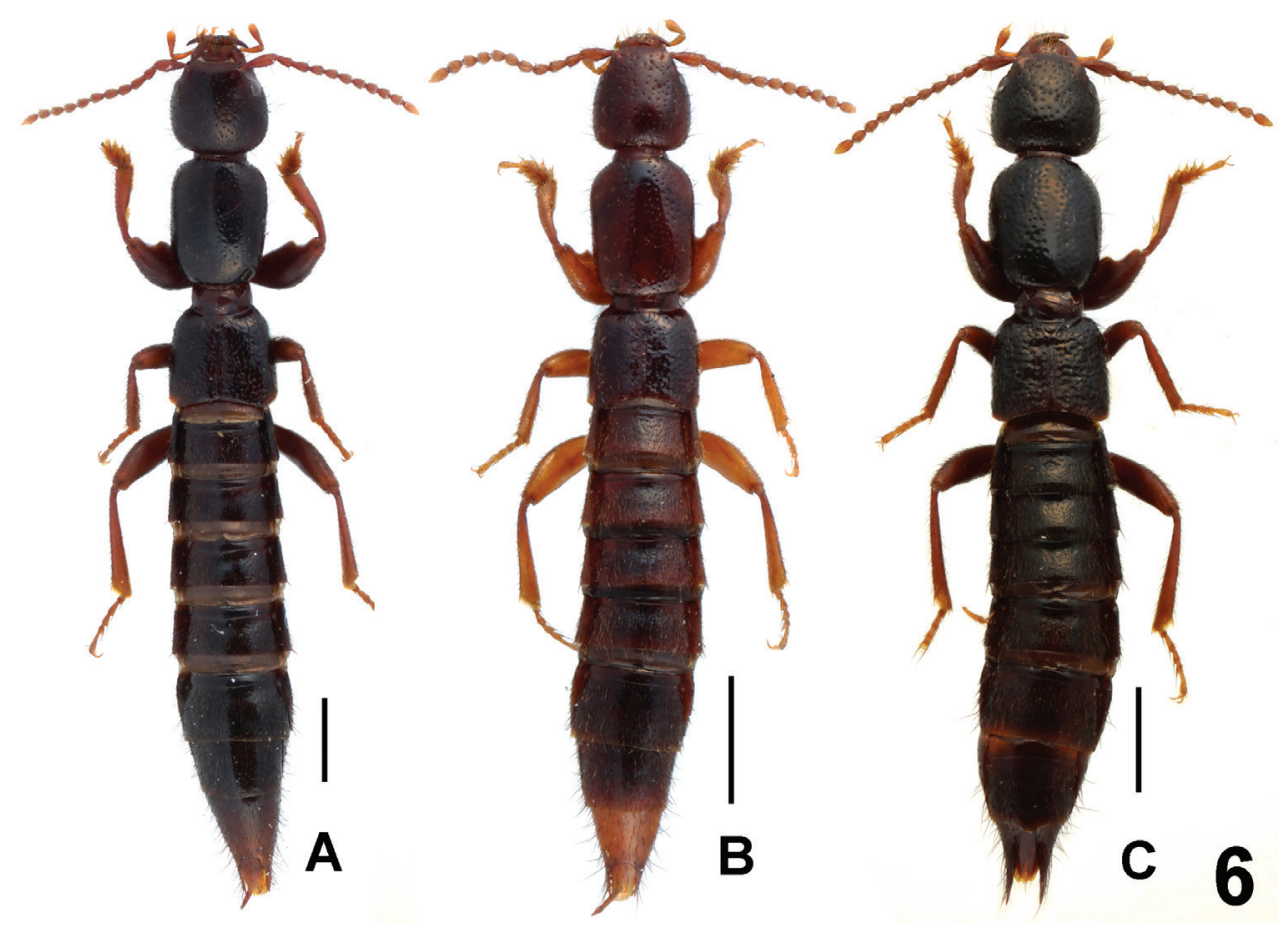

Figure 6. Habitus of Lathrobium spp., A L. obscurum B L. yinziweii C L. illustre. Scale bars: $1.0 \mathrm{~mm}$.

the long apical portion of the dorsal plate of the aedeagus and the absence of a distinct posterior excision of the male sternite VIII. It is distinguished from the other representatives of this group by the shape and chaetotaxy of the male sternites VII, as well as by with membranous structures in the internal sac of aedeagus.

\section{Lathrobium yinziweii Peng and $\mathrm{Li}$, sp. $\mathrm{n}$.} urn:Isid:zoobank.org:act:75FC14AD-DF7D-4EBE-95D2-18AC29FBBF1A http://species-id.net/wiki/Lathrobium_yinziweii

Figs 6B, 8, 15

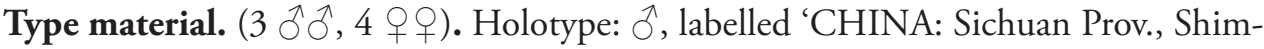
ian County, Liziping. Yele, $28^{\circ} 54^{\prime} \mathrm{N}, 102^{\circ} 13^{\prime} \mathrm{E}, 15 . v i i .2012$ alt. 2,600 m, Dai, Peng $\&$ Yin leg.' (SNUC). Paratypes: $2 \hat{\jmath} \widehat{O}^{\lambda}, 4$ 우우, same label data as holotype (SNUC).

Description. Measurements and ratios : BL 5.50-6.89, FL 2.40-2.82, HL 0.720.79, HW 0.75-0.78, PL 0.96-1.07, PW 0.77-0.82, EL 0.51-0.57, AL 1.67-1.72, HL/HW 0.96-1.01, HW/PW 0.95-0.97, HL/PL 0.73-0.76, PL/PW 1.25-1.30, EL/ PL 0.52-0.54.

Habitus as in Fig. 6B. Body light brown with paler apex, legs yellowish brown, antennae light brown. 


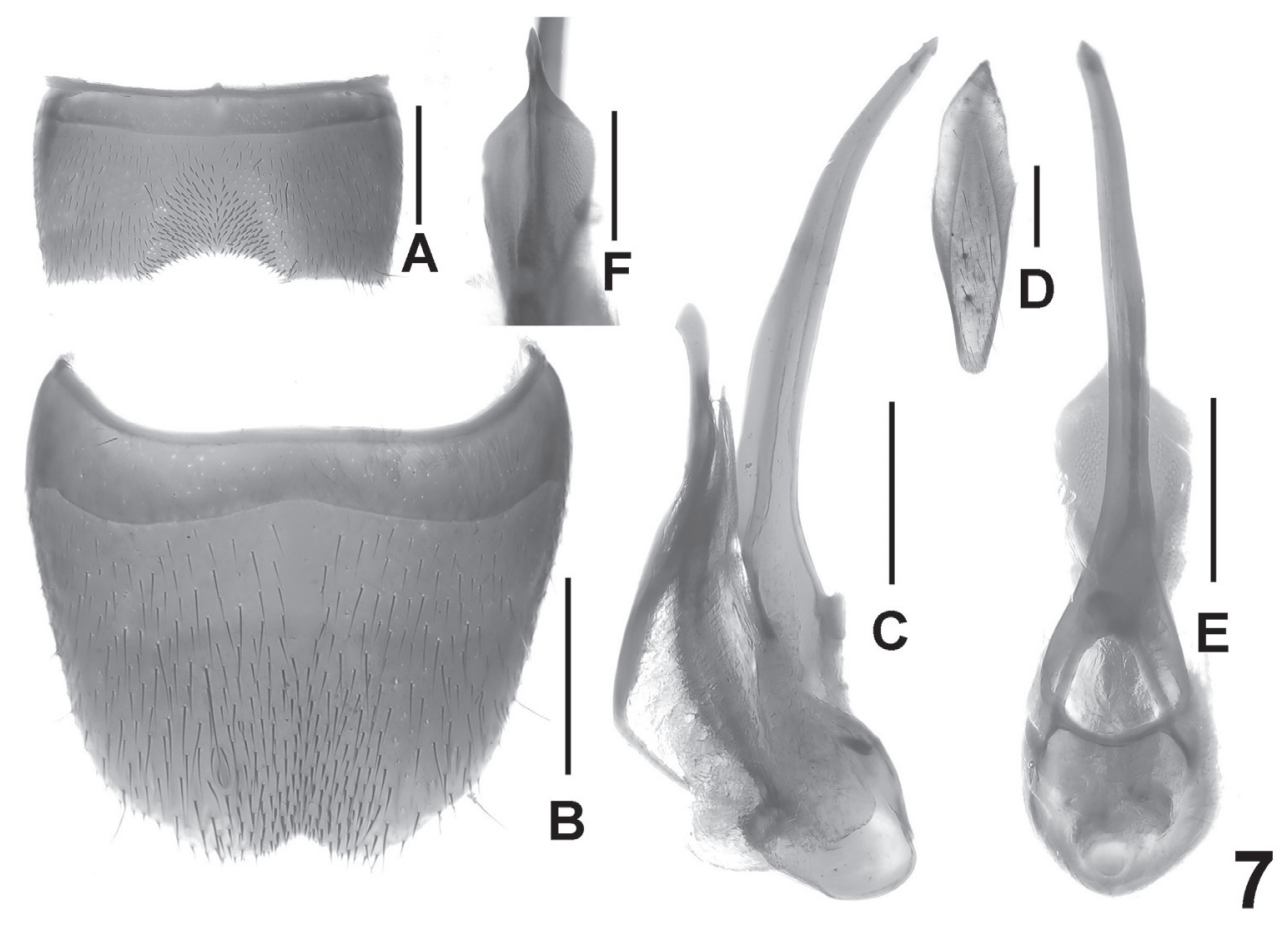

Figure 7. Lathrobium obscurum. A male sternite VII B male sternite VIII C aedeagus in lateral view D male sternite IX $\mathbf{E}$ aedeagus in ventral view $\mathbf{F}$ apical portion of aedeagus in dorsal view. Scale bars: $0.5 \mathrm{~mm}$.

Head subquadrate (HL/HW 0.96-1.01); punctation moderately coarse and sparse, sparser in median dorsal portion; interstices with fine microreticulation; eyes 1/5-1/4 times as long as postocular region in dorsal view.

Pronotum slender; punctation somewhat denser than that of head; impunctate midline broad; interstices without microreticulation.

Elytra 0.52-0.54 times as long as pronotum; punctation fine, shallow, and moderately dense. Hind wings completely reduced. Protarsi with moderately pronounced sexual dimorphism.

Abdomen with fine and dense punctation, that of tergite VII sparser than that of anterior tergites; interstices with shallow microsculpture; posterior margin of tergite VII without palisade fringe; tergite VIII with moderately pronounced sexual dimorphism.

Male. Tergite VIII with nearly truncate posterior margin; sternites III-VI unmodified; sternite VII (Fig. 8D) transverse and with shallow postero-median impression, pubescence very weakly modified, posterior margin concave in the middle; sternite VIII (Fig. 8E) broadly impressed along the middle, this impression with short modified setae, posterior margin shallowly concave in the middle; sternite IX (Fig. 8G) asymmetric; aedeagus as in Figs $8 \mathrm{~F}, 8 \mathrm{H}$; ventral process very long, slender, evenly curved, and apically indistinctly spear-shaped; basal portion of dorsal plate very short; internal sac with membranous structures and usual ring-shaped structure. 


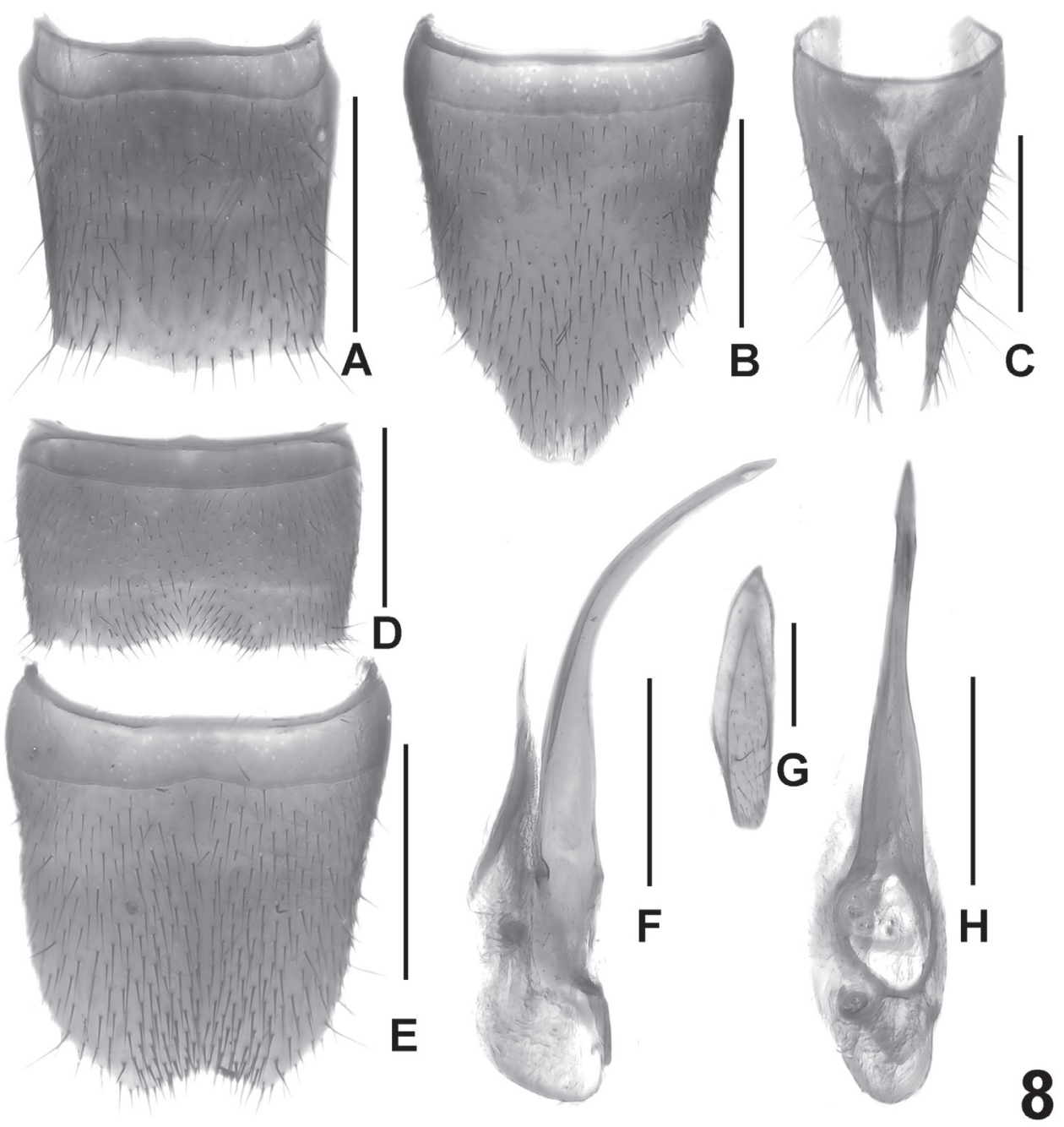

Figure 8. Lathrobium yinziweii. A female tergite VIII B female sternite VIII C female tergites IX-X. D male sternite VII E male sternite VIII $\mathbf{F}$ aedeagus in lateral view $\mathbf{G}$ male sternite IX $\mathbf{H}$ aedeagus in ventral view. Scale bars: $0.5 \mathrm{~mm}$.

Female. Posterior margin of tergite VIII (Fig. 8A) weakly convex; sternite VIII (Fig. 8B) much longer than tergite VIII and rather narrowly produced posteriorly; tergites IX-X (Fig. 8C) long and slender, tergite X (Fig. 8C) 1.4 times as long as anteromedian portion of tergite IX (Fig. 8C).

Distribution and biological notes. This species is currently known only from the type locality. One male was collected by sifting bamboo leaves and humus from the floor of the bamboo forest (Fig. 15). The other specimens were collected by sifting litter of bamboo and rhododendron from the floor of a rhododendron forest at an altitude of $2,600 \mathrm{~m}$. 
Etymology. The species is named after Yin Zi-Wei, who collected the type specimens.

Comparative notes. Lathrobium yinziweii is evidently closely related to $L$. diffissum (Assing, in press b) from the Luoji Shan. Both species share an aedeagus of similar morphology (ventral process long, slender, curved, and apically indistinctly spear-shaped; basal portion of dorsal plate very short; internal sac without sclerotized structures), a similar shape of the male sternite VII and sternite VIII (the posterior margin concave in the middle), a male sternite VIII with dense, but not distinctly modified pubescence, and a long and undivided antero-median portion of the female sternite IX. Lathrobium yinziweii is distinguished by the shape of the male sternite VIII (not transverse and with posterior excision), by the morphology of the aedeagus (ventral process evenly curved and slender; dorsal plate longer), by the shape of female sternite VIII, and by the long and slender female tergite IX-X.

\section{Lathrobium illustre Peng \& Li, sp. n.}

urn:Isid:zoobank.org:act:D980B711-7DFD-458C-8DA5-F1181F6F38FC http://species-id.net/wiki/Lathrobium_illustre

Figs 6C, 9, 15

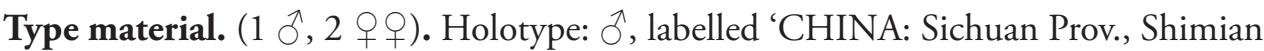
County, Liziping. Yele, $28^{\circ} 54^{\prime} \mathrm{N}, 102^{\circ} 13^{\prime} \mathrm{E}, 15 . v i i .2012$ alt. 2,600 m, Dai, Peng \& Yin leg.' (SNUC). Paratypes: 2 + 9 , same label data as holotype (SNUC).

Description. Measurements (in mm) and ratios: BL 7.84-9.23, FL 3.34-3.77, HL 1.02-1.05, HW 1.11-1.15, PL 1.44-1.50, PW 1.18-1.22, EL 0.74-0.78, AL 1.76, HL/HW 0.91-0.92, HW/PW 0.94, HL/PL 0.70-0.71, PL/PW 1.22-1.23, EL/ PL 0.51-0.52.

Habitus as in Fig. 6A. Body dark brown with paler apex, legs and antennae dark brown to light brown.

Head weakly transverse; punctation coarse and moderately sparse, sparser in median dorsal portion; interstices with fine microreticulation; eyes 1/4-3/8 times as long as postocular region in dorsal view.

Pronotum weakly convex in dorsal view; punctation somewhat denser than that of head; impunctate midline broad; interstices without microreticulation and shining.

Elytra $0.51-0.52$ times as long as pronotum; punctation fine, shallow, and moderately dense. Hind wings completely reduced. Protarsi with weakly pronounced sexual dimorphism.

Abdomen with fine and dense punctation, that of tergite VII sparser than that of anterior tergites; interstices with shallow microsculpture; posterior margin of tergite VII without palisade fringe; tergite VIII without sexual dimorphism; posterior margin broadly convex (Fig. 9A).

Male. Sternites III-VI unmodified; sternite VII (Fig. 9D) transverse, with median impression of triangular shape posteriorly, this impression with numerous distinctly modified, short and stout black setae; posterior margin distinctly concave in the middle; sternite 


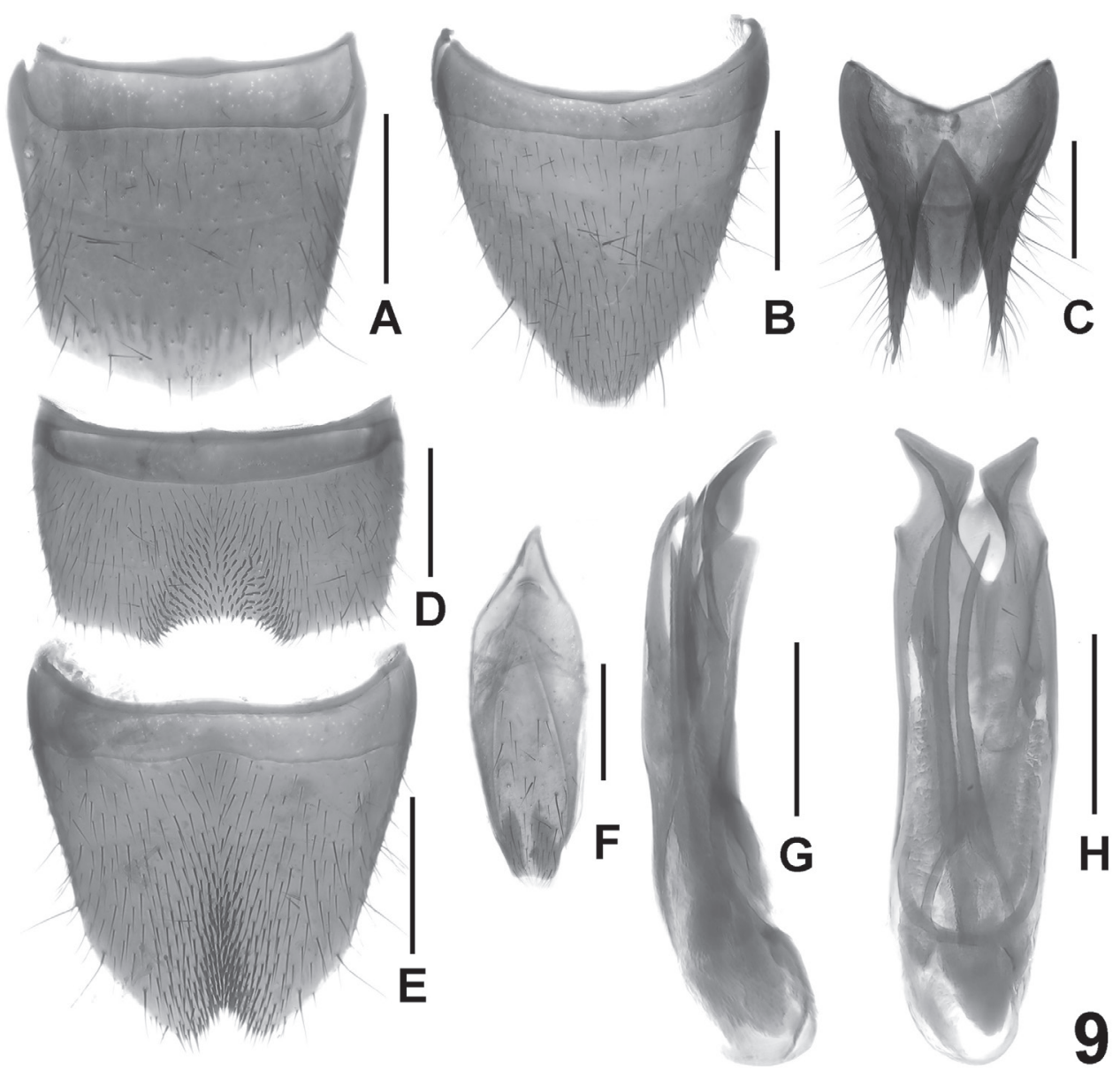

Figure 9. Lathrobium illustre. A female tergite VIII B female sternite VIII C female tergites IX-X. D male sternite VII E male sternite VIII $\mathbf{F}$ male sternite IX $\mathbf{G}$ aedeagus in lateral view $\mathbf{H}$ aedeagus in ventral view. Scale bars: $0.5 \mathrm{~mm}$.

VIII (Fig. 9E) impressed along the middle, this impression with dense short setae, posterior excision small and nearly V-shaped; sternite IX (Fig. 9F) symmetric; aedeagus as in Figs 9G, 9H; ventral process bilobed apically, asymmetric and of distinctive shape; dorsal plate long and sclerotized; internal sac with two long and slender sclerotized spines.

Female. Sternite VIII (Fig. 9B) much longer than tergite VIII, distinctly produced posteriorly; tergite $\mathrm{X}$ (Fig. 9C) 5.7 times as long as antero-median portion of tergite IX (Fig. 9C).

Distribution and biological notes. This species is currently known only from the type locality. The specimens were collected by sifting bamboo leaves and humus from the floor of a bamboo forest at an altitude of 2,600 m (Fig. 15).

Etymology. The specific epithet (Latin, adjective: shining) alludes to the shining pronotum. 
Comparative notes. Based on the apically bilobed ventral process and the anteriorly short and undivided median portion of the female tergite IX, L. illustre may belong belongs to the L. fissispinosum group. It is distinguished from the other representatives of this group by the shining pronotum, the shape and chaetotaxy of the male sternite VII and male sternite VIII, as well as by the morphology of the aedeagus.

\section{Lathrobium micangense Peng \& Li, sp. n.}

urn:Isid:zoobank.org:act:EF416164-BE8D-437F-8DD7-ABDE4F4BB91A http://species-id.net/wiki/Lathrobium_micangense

Figs 10A, 11, 16

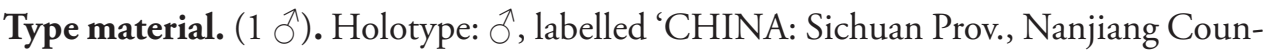
ty Mt. Micangshan, $32^{\circ} 39^{\prime} \mathrm{N} 107^{\circ} 01^{\prime} \mathrm{E}, 27 . i v .2008$ alt. 1,800 m, Huang \& Xu leg.' (SNUC).

Description. Measurements (in mm) and ratios: BL 6.78, FL 2.68, HL 0.83, HW 0.85, PL 1.11, PW 0.93, EL 0.56, AL 1.46, HL/HW 0.98, HW/PW 0.91, HL/PL 0.75, PL/PW 1.19, EL/PL 0.50.

Habitus as in Fig. 10A. Body reddish brown with paler apex, legs light brown, antennae reddish brown to yellowish brown.

Head subquadrate; punctation moderately coarse and sparse, sparser in median dorsal portion; interstices with fine microreticulation; eyes $1 / 4$ times as long as postocular region in dorsal view.

Pronotum nearly parallel-sided; punctation somewhat denser than that of head; impunctate midline broad; interstices without microsculpture.

Elytra 0.50 times as long as pronotum; punctation moderately dense, defined or weakly defined. Hind wings completely reduced.

Abdomen with fine and dense punctation, that of tergite VII sparser than that of anterior tergites; interstices with shallow microsculpture; posterior margin of tergite VII without palisade fringe.

Male. Sternites III-VI unmodified; sternite VII (Fig. 11A) transverse and deeply impressed in postero-median portion, this impression with several long dark setae, posterior margin weakly concave in the middle; sternite VIII (Fig. 11B) distinctly asymmetric and broadly impressed in postero-median portion, this impression with dense dark long setae, posterior margin broadly concave; sternite IX (Fig. 11G) asymmetric; aedeagus as in Figs 11D, 11E; ventral process long and asymmetric in ventral view; dorsal plate long and thin; internal sac with straight moderately sclerotized spine.

Female. Unknown.

Distribution and biological notes. The species is known only from one locality in Micang Shan, Sichuan. The holotype was collected by sifting dry leaf litter and moss on a southward slope with Prunus at an altitude of 1,800 m (Fig. 16).

Etymology. The species is named after its type locality: "Micang Shan". 


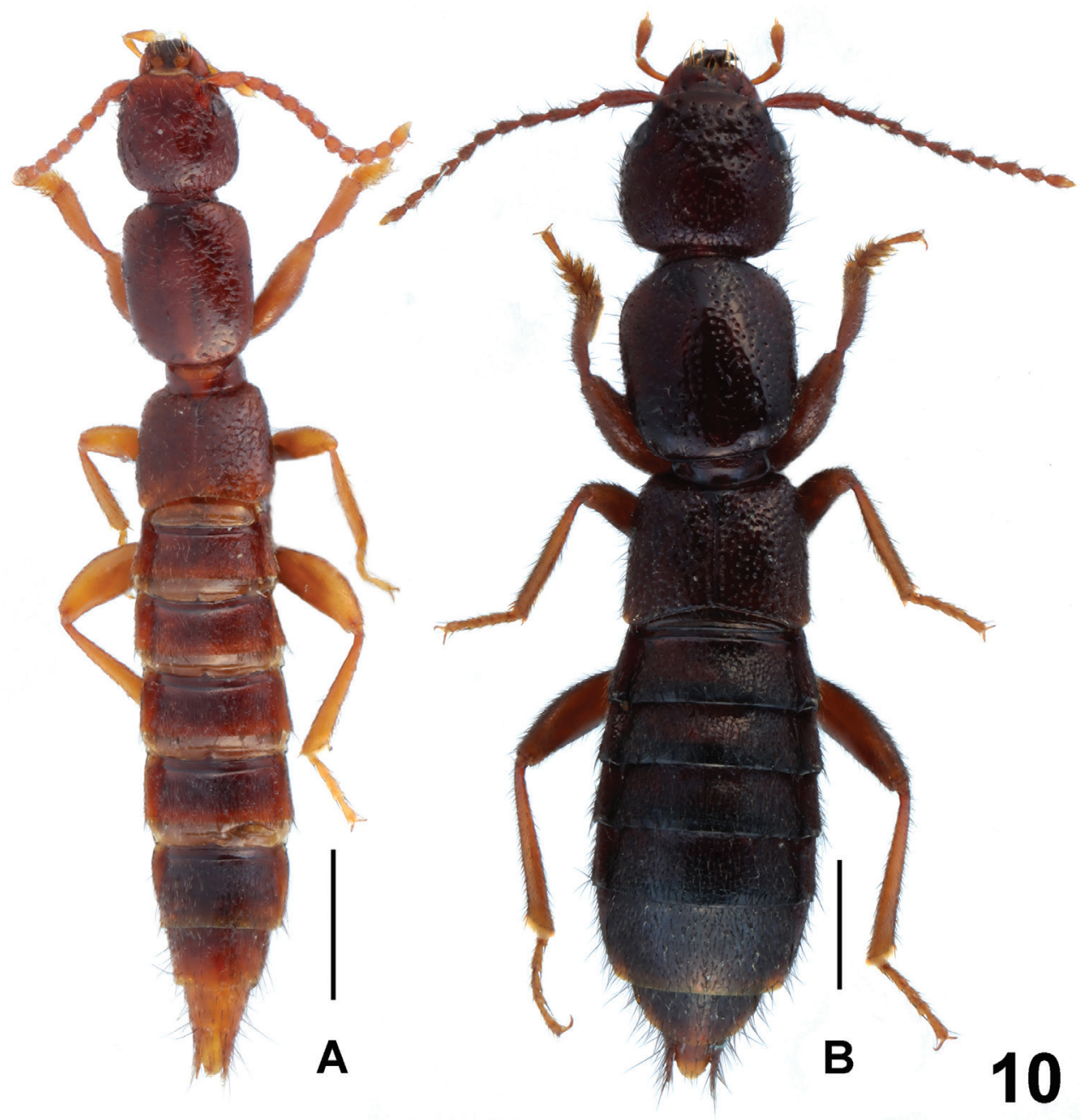

Figure 10. Habitus of Lathrobium spp., A L. micangense B L. agglutinatum. Scale bars: $1.0 \mathrm{~mm}$.

Comparative notes. Based on the morphology of the aedeagus (the shapes and chaetotaxy of the male sternites VII and VIII, presence of a moderately sclerotized spine in the internal sac, asymmetric ventral process), L. micangense belongs to the L. fissispinosum group. The morphology of the ventral process and the similar shape, the chaetotaxy of the male sternite VII and the asymmetric male sternite VIII suggest that it is closely related to L. longispinosum, from which L. micangense differs by the smaller body, the arrangement of the modified setae of the male sternite VIII, the shapes of the ventral process and the dorsal plate of the aedeagus, and the straight moderately sclerotized internal spine of the aedeagus (L. longispinosum: spine weakly curved). 

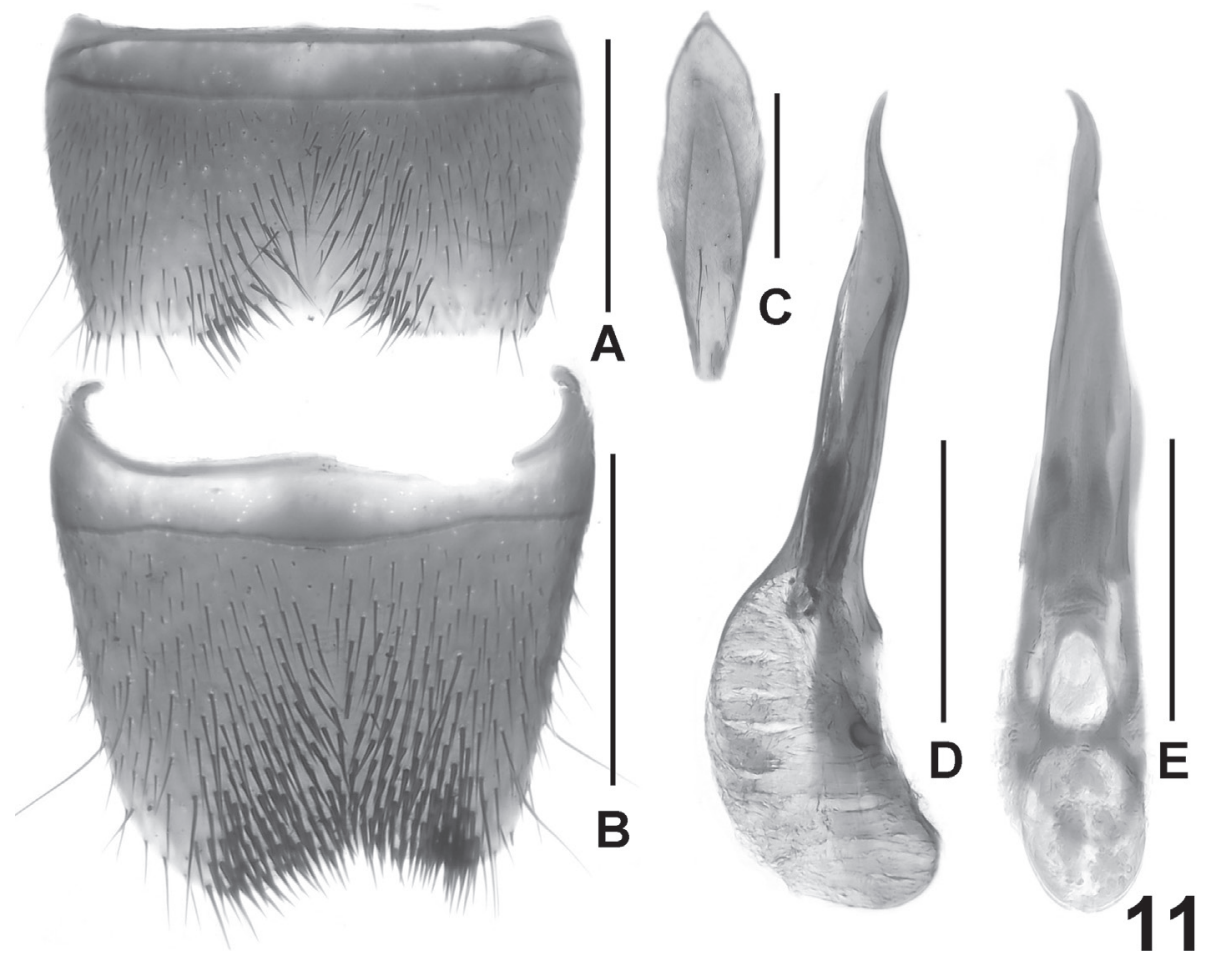

Figure I I. Lathrobium micangense. A male sternite VII B male sternite VIII C male sternite IX D aedeagus in lateral view $\mathbf{E}$ aedeagus in ventral view. Scale bars: $0.5 \mathrm{~mm}$.

\section{Lathrobium agglutinatum Assing \& Peng, sp. n.}

urn:lsid:zoobank.org:act:4DBEE816-245C-4921-828B-F807A5F32488

http://species-id.net/wiki/Lathrobium_agglutinatum

Figs 10B, 12, 17

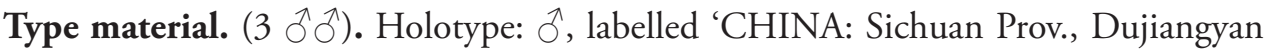
City, Mt. Qingchengshan, 30 $57^{\prime} \mathrm{N}, 103^{\circ} 28^{\prime} \mathrm{E}, 30 . v i i .2012$ alt. 1,700 m, Dai, Peng \& Yin leg.' (SNUC). Paratypes: 1 $\widehat{\alpha}$, same label data as holotype (SNUC); 10 , 'China (Sichuan) 1999, Qingcheng-shan, (Umg. Heavenly Old Village) 1000-1300 m, 18./20.VI. Heinz leg.' (cAss).

Description. Measurements (in $\mathrm{mm}$ ) and ratios: BL 7.78-9.51, FL 4.00-4.28, HL 1.25-1.28, HW 1.38-1.40, PL 1.63-1.68, PW 1.40-1.43, EL 0.81-0.83, AL 1.65-1.70, HL/HW 0.91, HW/PW 0.98-0.99, HL/PL 0.77, PL/PW 1.16-1.17, EL/PL 0.49-0.50.

Habitus as in Fig. 5A. Body dark brown with paler apex, legs and antennae brown to light brown.

Head subquadrate; punctation dense and coarse; interstices with fine microreticulation; eyes 0.3 times as long as postocular region in dorsal.

Pronotum with weakly convex lateral margins in dorsal view; punctation somewhat sparser than that of head; impunctate midline narrow; interstices without microsculpture. 


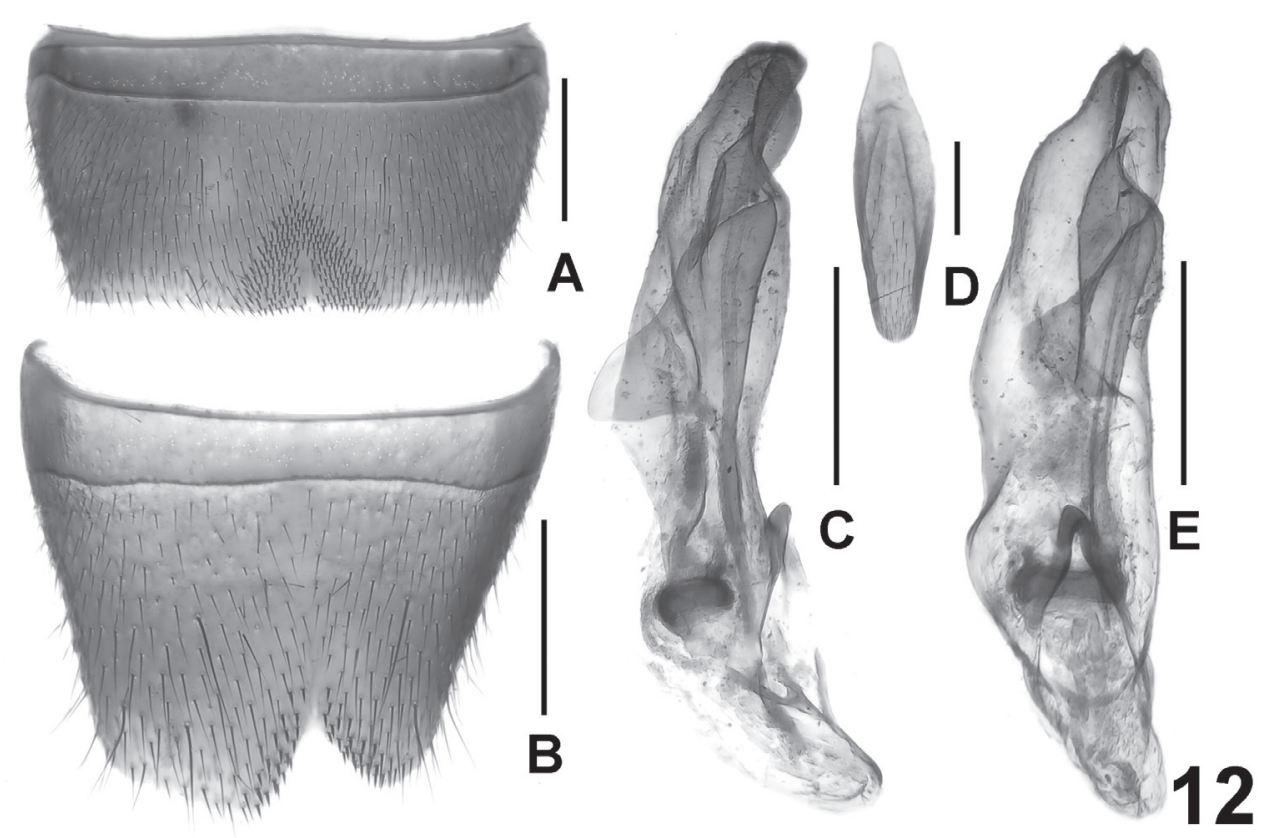

Figure 12. Lathrobium agglutinatum. A male sternite VII B male sternite VIII C aedeagus in lateral view D male sternite IX E aedeagus in ventral view. Scale bars: $0.5 \mathrm{~mm}$.

Elytra 0.49-0.50 times as long as pronotum; punctation shallow and much denser than that of pronotum; interstices without distinct microsculpture. Hind wings reduced.

Abdomen much broader than elytra, with fine and dense punctation, that of tergite VII sparser than that of anterior tergites; interstices with shallow microsculpture; posterior margin of tergite VII without palisade.

Male. Sternites III-VI unmodified; sternite VII (Fig. 12A) strongly transverse and with short dark seta in triangular postero-median impression, posterior margin nearly truncate; sternite VIII (Fig. 12B) transverse and weakly impressed in postero-median portion, posterior excision pronounced, deep and asymmetric, anterior margin of this excavation with short dark setae; sternite IX (Fig. 12D) asymmetric; aedeagus as in Figs 12C, 12E; ventral process and dorsal plate fused; basal portion of aedeagus small; internal sac with usual ring-shaped structure.

Female. Unknown.

Distribution and biological notes. The species is known only from one locality in the Qingcheng Shan, Sichuan. Two specimens were collected by sifting leaf litter and humus from the floor of a hardwood forest with Cherokee rose and Rubus at an altitude of $1,700 \mathrm{~m}$ (Fig. 17).

Etymology. The specific epithet is the past participle of the Latin verb agglutinare (to glue together) and alludes to the fused ventral process and dorsal plate of the aedeagus.

Comparative notes. Lathrobium agglutinatum is undoubtedly closely related to $L$. conexum and belongs to the L. iunctum group (Assing et al., 2013). This conclusion is 


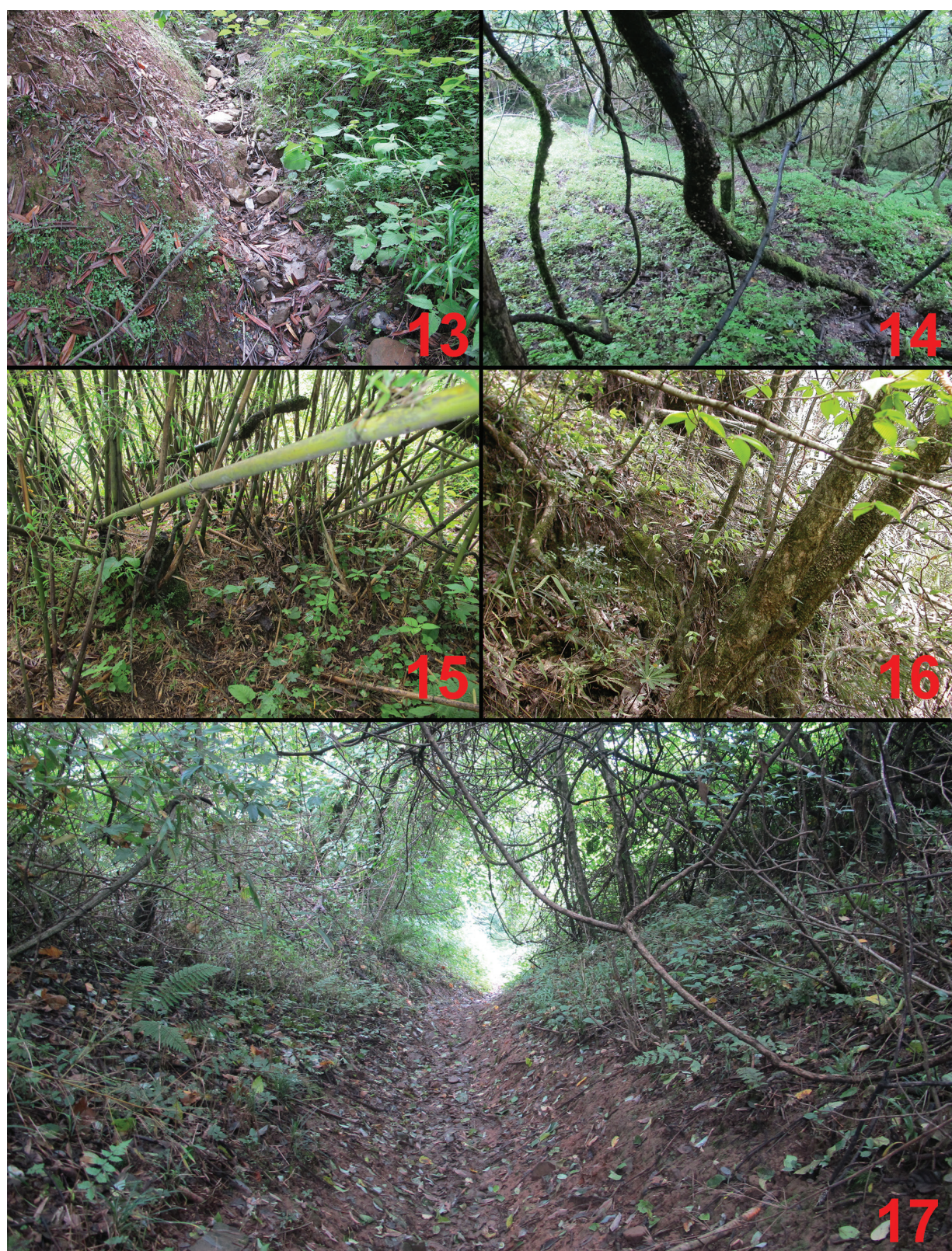

Figures 13-I7. Habitats of the new species. I3 Erlang Shan, alt. 2,200-2,300 m (L. erlangense sp. n.) I4 Labahe Natural Reserve, alt. 2,200-2,300 m (L. blandum sp. n.) I5 Yele, alt. 2,600 m (L. illustre sp. n., L. yinziweii sp. n. and L. yelense sp. n.) I6 Micang Shan, alt. 1,800 m (L. micangense sp. n.) 17 Qingcheng Shan, alt. 1,700 m (L. agglutinatum sp. n.).

supported by the similarly derived structure of the aedeagus (ventral process and dorsal plate fused, asymmetric, and slender; basal portion small; internal sac with small and weakly sclerotized basal sclerite); the similarly derived shape and chaetotaxy of the 
male sternite VIII (posterior excision asymmetric, the anterior margin of this excavation with short dark setae), and by the extremely similar external characters. Both species are best distinguished by the completely different shape and chaetotaxy of the male sternite VII and by the differently shaped apex of the aedeagus. For illustrations of the species of the L. iunctum group from the Emei Shan see Assing et al. (2013).

\section{Acknowledgements}

All the collectors mentioned in the text are acknowledged for their field work. Two anonymous reviewers are thanked for comments on a previous version of the manuscript. We are most grateful to Volker Assing (Hannover) for making an unpublished manuscript containing descriptions of several species from Sichuan available to us to avoid overlap, for providing an additional type specimen of one newly described species, and for his comments on an earlier version of the manuscript. Moreover, we thank Wang Lao-er for his support during our field work. The study is supported by the National Natural Science Foundation of China (No. 31101659 and No. 31172134, 31201734), the Foundation of Shanghai Municipal Education Commission (No. 12YZ077 and No. 13YZ062) and Shanghai Normal University (SK201234, DZL125 and B-9013-11-003127).

\section{References}

Assing V (in press a) On the Lathrobium fauna of China V. New species and additional records from Yunnan (Coleoptera: Staphylinidae: Paederinae). Beiträge zur Entomologie 63 (1).

Assing V (in press b) On the Lathrobium fauna of China IV. Six new species from Sichuan (Coleoptera: Staphylinidae: Paederinae). Linzer Biologische Beiträge 45 (1).

Assing V (in press c) On the Lathrobium fauna of China III. New species and additional records from various provinces (Coleoptera: Staphylinidae: Paederinae). Beiträge zur Entomologie $63(1)$.

Assing V (in press d) On the Lathrobium fauna of China I. The species of the Qinling Shan, the Daba Shan, and adjacent mountain ranges (Coleoptera: Staphylinidae: Paederinae). Bonn Zoological Bulletin 62 (1).

Assing V, Peng Z, Zhao M-J (2013) On the Lathrobium fauna of the Emei Shan, Sichuan, China (Coleoptera, Staphylinidae, Paederinae). ZooKeys 277: 47-67. doi: 10.3897/zookeys.277.4671

Peng Z, Li L-Z, Zhao M-J (2012) Three new species of Lathrobium Gravenhorst (Coleoptera: Staphylinidae: Paederinae) from Sichuan, Southwest China. ZooKeys 205: 33-44. doi: 10.3897/zookeys.205.3148

Schülke M (2002) A new microphthalmous Lathrobium (Coleoptera, Staphylinidae, Paederinae) from Sichuan. Special Bulletin of the Japanese Society of Coleopterology 5: 251-254. Yang Q-Z (1988) The characteristics of the regional differentiation of the forest in Sichuan Province. Mountain Research 6 (4): 210-218. 